\title{
The effect of topic importance and attitude similarity-dissimilarity on attraction in an intrastranger design'
}

DONN BYRNE, DEPARTMENT OF PSYCHOLOGY, UNIVERSITY OF TEXAS, Austin, Tex. 78712, OLIVER LONDON, COLORADO STATE UNIVERSITY, AND WILLIAM GRIFFITT, UNIVERSITY OF HAWAII

Although topic importance has been proposed as a crucial factor in the relationship between attitude similarity and attraction, two previous experiments failed to confirm this proposition. In the present investigation an intrastranger design was used in which two levels of attitude similarity were created by systematically assigning topics of differential importance as the similar and dissimilar items. Both the similarity variable and the importance variable significantly influenced attraction responses. It was shown that importance effects can be expected only when topics heterogeneous in importance are associated with one stranger.

In the well established relationship between the proportion of similar attitudes expressed by a stranger and the attraction of $S$ toward him, the role of topic importance as a crucial element has frequently been suggested (e.g., Byrne, 1961; Newcomb, 1956). Empirical support for an importance effect has, however, been lacking.

Two experiments have failed in the attempt to verify differential response to similarity-dissimilarity on important vs trivial issues (Byrne \& Nelson, 1964, 1965). In the first, 56 attitude items were scaled with respect to importance and then divided into four 14-item attitude measures representing four levels of importance. Ss responded to one of these scales and later were asked to evaluate a stranger who had supposedly filled out the same scale. Two levels of similarity and the four levels of importance were represented. Attraction was found to be significantly influenced by attitude similarity but not by topic importance nor by the interaction. Since each $S$ responded to only one level of importance, an adaptation effect was suggested as responsible for the failure. In the second experiment, therefore, each $S$ was given all four 14-item scales and later responded to four strangers. The stranger was either completely similar to or dissimilar from the $S$, and $S$ responded to four strangers each representing one level of topic importance. The results were identical to those of the first investigation: a highly significant similarity effect and no importance effect.

It is clear that within the limits of the reported designs, topic importance is irrelevant as a determinant of attraction. The plausibility of topic importance as a variable led to a consideration of aspects of the experimental design which could have been responsible for obscuring an importance effect. First, it seemed possible that Ss in the second experiment were assuming that the stranger exhibited the same degree of similarity on all 56 items as was present on the 14 items under examination. To control for this possibility, it would be necessary to present all 56 of a single stranger's responses to the S. Second, it was possible that individual differences in judgments of topic importance served to nullify the experimental manipulation. If so, it would be necessary to define importance according to the values of the individual $S$ rather than by using the scaled values based on the judgments of others. In the present experiment, therefore, the importance hypothesis was tested in an intrastranger design in which every stranger was represented on all 56 items. At a given similarity level, agreement was on important issues and disagreement on unimportant ones or vice versa. In addition, for half of the Ss importance was defined by the scaled values used in the previous studies while for the other half importance would be defined individually on the basis of S's own judgments.

Method. A group of 80 undergraduates was pretested on the 56-item attitude scale and later assigned to one of eight experimental conditions. There were two levels of attitude similarity $(.25$ and .75$)$. Topic importance was manipulated by the choice of items on which the stranger was to be similar or dissimilar. For exampie, in the .25 condition the items of agreement were either the 14 most or 14 least important topics. Importance was defined by group judgments for half the Ss and by self-judgments for the other half. Attraction is measured on two rating scales the sum of which yields a score ranging from 2 to 14 .

Results. The mean attraction responses are presented in Table 1. Analysis of variance indicated both a significant similarity effect $(F=28.03, \mathrm{df}=1 / 72, \mathrm{p}<.001)$ and a significant importance effect $(F=10.09, \mathrm{~d} f=1 / 72, p<.003)$. The group vs self definition of importance did not influence attraction. In an intrastranger design, then, the importance hypothesis was finally confirmed.

Discussion. Why is there a discrepancy among the investigations of importance? The answer is provided by Clore \& Baldridge (in press) and is best explained after their data are examined. They obtained ratings of topic interest on the same 56 items, created three levels of stranger-subject similarity $(.25, .50$, and .75) with systematic assignment of interesting and uninteresting topics as agree or disagree, and obtained results parallel to the present ones. They then utilized a formula developed by Byrne \& Rhamey (1965) in which attraction is expressed as a positive linear function of weighted proportion of similar attitudes.

Specifically,

$$
\mathrm{Y}=\mathrm{m} \frac{\Sigma(\mathrm{S} \times \mathrm{M})}{\Sigma(\mathrm{S} \times \mathrm{M})+\Sigma(\mathrm{D} \times \mathrm{M})}+k
$$

in which $Y$ is attraction, $S$ and $D$ represent similar and dissimilar attitudes, and $M$ is a weighting coefficient reflecting the magnitude of effect of each item. For the most vs least interesting items. Clore and Baldridge derived weights of 3 to 1, applied the Byme-Rhamey formula, and obtained the usual linear relationship between proportion of weighted similar attitudes and attraction. Since interest ratings were found to correlate .80 with importance ratings, their weighting coefficients were applied to the present data. ${ }^{2}$ In addition, the same weights were employed with some earlier findings (Byrne, 1961) in which similarity was . 50 and importance was manipulated as in the present study. The results are best seen in Fig. 1 in which the data of all three experiments are plotted. Clearly, the weighting coefficients, developed in a sample of Illinois undergraduates to describe the effects of differential topic interest, hold well across the three sets of data, including the two Texas samples in which topic importance was manipulated.

Table 1

Mean Attraction Responses Toward Strangers at Two Levels of Attitude Similarity with Two Levels of Topic Importance

\begin{tabular}{lccc} 
& $\begin{array}{c}\text { Proportion of } \\
\text { Similar Attitudes }\end{array}$ & $\begin{array}{c}\text { Similar Items } \\
\text { More Important }\end{array}$ & $\begin{array}{c}\text { Similar Items } \\
\text { Less Important }\end{array}$ \\
\hline Topic Importance Based & .75 & 10.00 & 9.30 \\
on Group Judgment & .25 & 6.90 & 5.20 \\
Topic Importance Based & .75 & 10.40 & 6.20 \\
on Individual Judgment & .25 & 6.30 & 6.00 \\
\hline
\end{tabular}




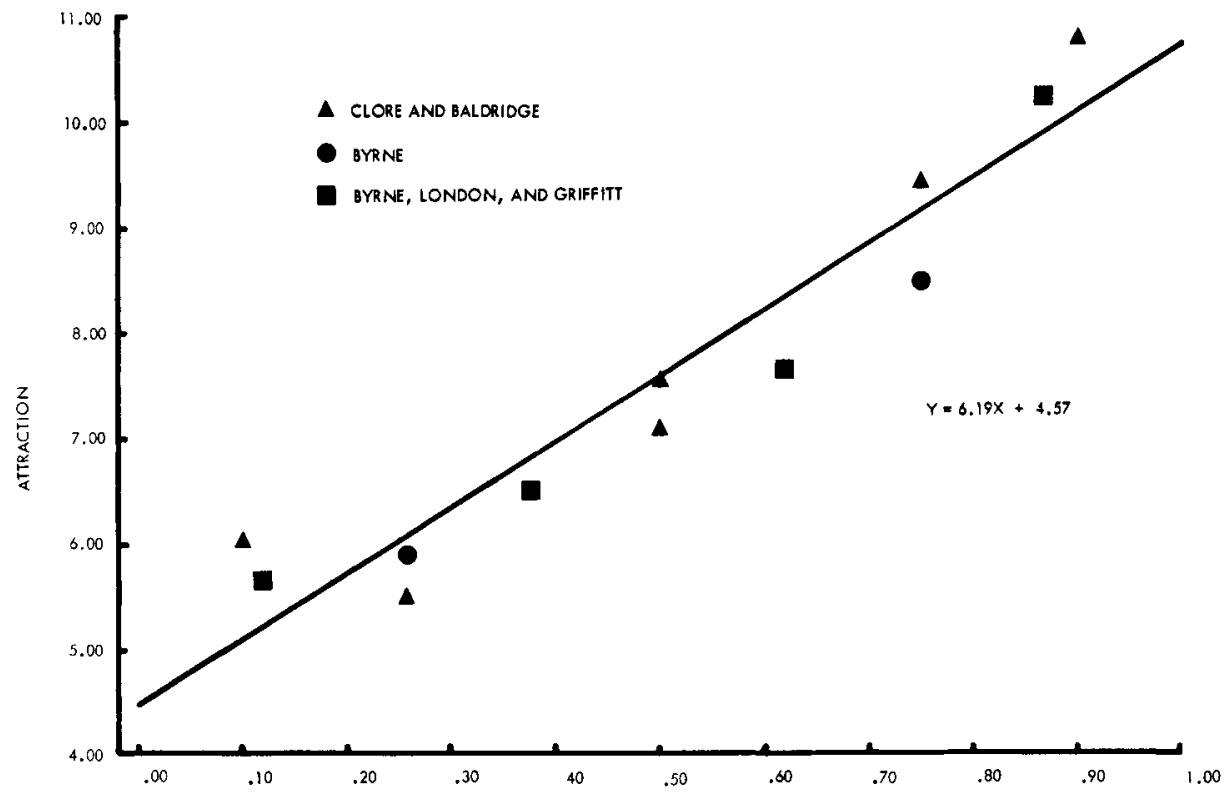

WEIGHTED PROPORTION OF SIMILAR ATTITUDES
Fig. 1. Attraction toward a stranger as a linear function of weighted proportion of similar attitudes with weighting coefficients corresponding to levels of topic importance and interest.
To return to the Byrne and Nelson investigations, importance had no effect because each $S$ responded to only one level of topic importance. It may be seen that, regardless of the weight of any one level, the Byrne-Rhamey formula predicts differential results only when differential weights are combined. Clore \& Bladridge (in press) further confirmed this formulation in a second experiment with homogeneous levels of topic interest and, as predicted, obtained only a similarity effect.

In brief, topic importance and/or interest is found to influence the similarity-attraction relationship but only when topics of differential weight are associated with a single stranger.

\section{REFERENCES}

BYRNE, D. Interpersonal attraction and attitude similarity. J. abnorm, soc. Psychol, 1961, 62, 713-715.

BYRNE, D., \& NELSON, D. Attraction as a function of attitude similaritydissimilarity: the effect of topic importance. Psychon. Sci, 1964, 1, 93-94. BYRNE, D., \& NELSON, D. The effect of topic importance and attitude similarity-dissimilarity on attraction in a multi-stranger design. Psychon. Sci, $1965,3,449-450$.

BYRNE, D., \& RHAMEY, R. Magnitude of positive and negative reinforcements as a determinant of attraction. J. pers. soc. Psychol, 1965, 2, 884-889.

CLORE, G. L., \& BALDRIDGE, B. Interpersonal attraction: the role of agreement and topic interest. J. pers. soc. Psychol, in press.

NEWCOMB, T. M. The prediction of intetpersonal attraction. Amer. Psychologist, 1956, 11, 575-586.

\section{NOTES}

1. This research was supported by Research Grant MH-11178-03 from the National Institute of Mental Health, United States Public Health Service.

2. Because the present experiment also utilized 28 topics of intermediate importance, their weights were assumed to fall halfway between those of most and least. 